\title{
Pre- and Postoperative Evaluation of Patients with End-Stage Heart Failure Undergoing Cardiac Transplant - a Descriptive Study
}

\author{
Costel Dumitru, Dana Ghiga², Septimiu Voidazan³, Alexandra Grosan, Dan Simpalean5, Anca Sin6 \\ 1 "George Emil Palade" University of Medicine, Pharmacy, Science and Technology, Târgu Mureș, Romania \\ 2 Discipline of Methodology of Medical Scientific Research, "George Emil Palade" University of Medicine, Pharmacy, Science and \\ Technology, Târgu Mureș, Romania \\ 3 Discipline of Epidemiology, "George Emil Palade" University of Medicine, Pharmacy, Science and Technology, Târgu Mureș, Romania \\ 4 Discipline of Pharmacology and Clinical Pharmacy, "George Emil Palade" University of Medicine, Pharmacy, Science and \\ Technology, Târgu Mureș, Romania \\ 5 "Filantropia" Clinical Hospital, Bucharest, Romania \\ 6 Discipline of Cell Biology, "George Emil Palade" University of Medicine, Pharmacy, Science and Technology, Târgu Mureș, Romania
}

\section{CORRESPONDENCE}

\section{Costel Dumitru}

Str. Gheorghe Marinescu nr. 38

540139 Târgu Mureș, Romania

Tel: +40 265215551

E-mail: costimv@yahoo.com

\section{ARTICLE HISTORY}

Received: July 30, 2020

Accepted: August 30, 2020

Dana Ghiga • Str. Gheorghe Marinescu nr. 38, 540139 Târgu Mureș, Romania. Tel: +40 265215 551, E-mail: valentinaghiga@yahoo.com

Septimiu Voidazan • Str. Gheorghe Marinescu nr. 38 540139 Târgu Mures, Romania. Tel: +40 265215 551, E-mail: septi_26_07@yahoo.com

Alexandra Grosan • Str. Gheorghe Marinescu nr. 38 540139 Târgu Mureș, Romania. Tel: +40 265215 551, E-mail: alexandra.grosan@yahoo.com

Dan Simpalean • Blv. Ion Mihalache nr. 11, 011171 București, Romania. Tel: +40 2131889 37, E-mail: dansimpalean@gmail.com

Anca Sin • Str. Gheorghe Marinescu nr. 38, 540139 Târgu Mureș, Romania. Tel: +40 265215 551, E-mail: anka_sinn@yahoo.com

\begin{abstract}
Background: Heart transplantation is still the treatment of choice in patients with end-stage heart failure, refractory to medical treatment, in NYHA class III and IV, with dilated cardiomyopathy of various etiologies, including post-myocardial infarction. Objective: The aim of the study was to provide a descriptive analysis of the clinical, laboratory, and imaging parameters of patients undergoing heart transplantation during the pre- and postoperative period, as well as postoperative complications (including infections) and death rates. Material and methods: The variables collected from 53 patients who underwent a heart transplant were: age at heart transplant, gender, diagnosis at hospitalization, comorbidities, pre- and postoperative virology, pre- and postoperative laboratory analyses, pre- and postoperative echocardiography, post-transplant infections, complications, and treatment before and after the surgery. Results: Mean age at the time of transplant was $40.72 \pm 14.07$ years, and the majority (84.91\%) of patients were males. The mean age of the donors was $31.92 \pm 10.59$ years. A proportion of $60.40 \%$ of patients were included in functional class NYHA IV, and $98.1 \%$ presented dilative cardiomyopathy of which $49.06 \%$ was due to previous myocardial infarction. No significant differences were observed between preand postoperative viral and bacterial serology. Left ventricular ejection fraction was significantly higher in the transplanted heart, and cardiac chamber diameters were significantly smaller after the transplant. Postoperative complications included 7 confirmed infections and 16 deaths, of which 5 had occurred during the surgical procedure. Conclusions: The present study brings important information in regard to the pre- and postoperative evaluation of patients with end-stage heart failure undergoing cardiac transplantation, from a clinical, laboratory, and imaging point of view, as well as in regard to postoperative complications and death.
\end{abstract}

Keywords: end-stage heart failure, cardiac transplant, preoperative, postoperative, clinical, laboratory, viral and bacterial serology 


\section{INTRODUCTION}

It is undeniable that the medical field evolves every year, and several improvements have been reported in the medical therapy and mechanical circulatory support of patients with advanced heart failure (HF). ${ }^{1}$ Despite these therapeutic advancements, heart transplantation is still the treatment of choice in patients with end-stage HF, refractory to medical treatment, in NYHA class III and IV, with dilated cardiomyopathy of various etiologies, including post-myocardial infarction. ${ }^{2,3}$ The prevalence of cardiovascular disease is increasing worldwide, including in Romania. ${ }^{4}$ It is estimated that $2-3 \%$ of the adult population worldwide suffers from heart failure, and 1 in 2,500 patients is diagnosed with dilated cardiomyopathy. ${ }^{5,6}$ Due to the increasing prevalence of $\mathrm{HF}$ and the increasing survival rates of HF patients due to complex pharmacological and device therapies, the need for cardiac transplantation had also increased significantly.7-9

\section{AIM OF THE STUDY}

The aim of the study was to provide a descriptive analysis of patients undergoing heart transplantation with regard to pre-and postoperative clinical assessment, laboratory, and imaging testing, as well as postoperative complications and death rates.

\section{MATERIAL AND METHODS}

We conducted a retrospective study at the Institute of Cardiovascular Diseases and Transplant in Târgu Mureș, Romania, which included 53 patients who underwent cardiac transplantation for end-stage HF between 2000 and 2017. We collected and analyzed the following data from the medical files of patients: the age at which the transplant took place, patient gender, main diagnosis, comorbidities, laboratory tests conducted in the pre- and postoperative period (virology and bacterial testing, the degree of histocompatibility, biochemistry tests, hematological tests), echocardiography examination before and after surgery, information on the operative technique, post-transplant complications, and treatment.

The statistical analysis consisted of calculating means and standard deviations for quantitative variables, as well as proportions and percentages for qualitative variables. The statistical significance of the study was set at a threshold $\mathrm{p}$ value of 0.05 . The D'Agostino-Pearson test was applied to determine the distribution of quantitative data (Gaussian and non-Gaussian, respectively). For comparison of quantitative variables, Student's t test and the Wilcoxon test were used when appropriate, while Fisher's exact test and the chi-squared test were applied to determine the power of association between categorical variables.

The study was conducted in accordance with the principles stipulated in the Declaration of Helsinki. Informed consent was waived by the ethics committee of the institution, as the study was retrospective.

\section{RESULTS}

Fifty-three cardiac transplantations were performed between 2000 and 2017, most of them (20.75\%) in 2016, followed by 2006 (11.32\%) (Figure 1).

\section{Characteristics of the study population}

The mean age at which the transplant occurred was 40.72 \pm 14.07 years, the majority of patients were male (84.91\%) and with an urban provenience $(56.60 \%)$, and the mean body height and weight of the patients was $170.3 \pm 21.25$ $\mathrm{cm}$ and $73.68 \pm 21.17 \mathrm{~kg}$, respectively. The age of the donors was $31.92 \pm 10.59$ years, the majority $(66.67 \%)$ being male.

The majority of patients $(60.40 \%)$ were included in NYHA functional class IV, and most of them (98.1\%) presented dilated cardiomyopathy, out of which $49.06 \%$ had a history of myocardial infarction, and $36.54 \%$ had pulmonary hypertension. Comorbidities included type 2 diabetes $(9.62 \%)$, dyslipidemia $(7.55 \%)$, and various forms of hepatitis (5.66\%).

\section{Laboratory testing}

\section{Viral and bacterial serology}

Preoperative serum levels of hepatitis $B$ virus antigen $S$ (HBs Ag), anti-hepatitis B virus antibodies (anti-HBc $\mathrm{Ab}$ ), anti-hepatitis $\mathrm{C}$ virus antibodies (anti-HCV $\mathrm{Ab}$ ), anti-Treponema pallidum antibodies (anti-TP Ab), antiToxoplasma gondii IgM antibodies (anti-Toxop IgM Ab), anti-Cytomegalovirus IgM antibodies (Anti CMV IgM $\mathrm{Ab}$ ), anti-Mycoplasma antibodies (anti-My $\mathrm{Ab}$ ), and anti-human immunodeficiency virus antibodies (anti-HIV $\mathrm{Ab})$ were in most cases negative, while anti-Toxoplasma gondii IgG antibodies (anti-Toxop IgG Ab) (54.55\%) and anti-Cytomegalovirus IgG antibodies (anti-CMV IgG Ab) (51.11\%) were positive. Postoperatively, the results were similar to the preoperative evaluation, only the anti-Toxop IgG Ab (40.91\%) and anti-CMV IgG Ab (44.44\%) being positive (Table 1 ). 


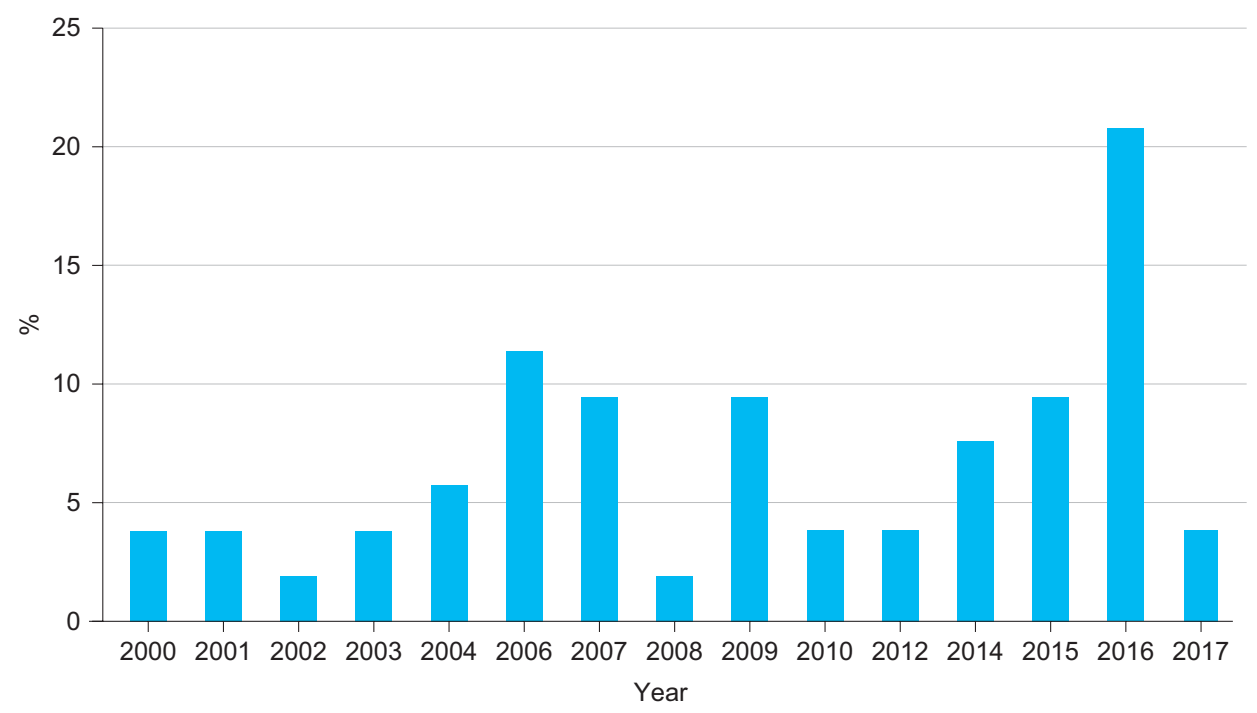

FIGURE 1. Frequency of heart transplantation at the Institute of Cardiovascular Diseases and Transplant, Târgu Mureș, Romania, in the 2000-2017 period

\section{Complete blood count and biochemical testing}

Following surgery, there was a significant decrease in hematocrit and hemoglobin levels due to intraoperative blood loss. However, creatinine, liver enzyme, and bilirubin levels were also significantly decreased (Table 2).

\section{Surgical techniques and postoperative complications}

Regarding the type of surgery, in most patients (75.47\%) an orthotopic cardiac transplant was performed, using the bicaval technique with extracorporeal circulation. In eight cases, a primary aortic anastomosis was required, and in two cases the extraction of an implantable cardioverter defibrillator was performed.
There were seven cases of post-transplant infection: two with Klebsiella pneumoniae, one with Clostridium difficile, one with Staphylococcus aureus, one with Methicillin-sensitive Staphylococcus aureus (MSSA), one with Staphylococcus epidermidis, and one with Pseudomonas aeruginosa.

\section{Pre- and postoperative echocardiography}

Left ventricular ejection fraction was significantly higher in the transplanted hearts, and the diameters of cardiac chambers were significantly lower on the postoperative echocardiographic examination (Table 3 ).

Regarding treatment with immunosuppressive drugs for the prevention of transplant rejection, most patients

TABLE 1. Pre- and postoperative viral and bacterial serology

\begin{tabular}{lcccc}
\hline & \multicolumn{2}{c}{ Preoperative } & \multicolumn{2}{c}{ Postoperative } \\
\cline { 2 - 5 } & Negative & Positive & Negative & Positive \\
\hline HBs Ag & $45(100 \%)$ & $0(0 \%)$ & $N A$ & $N A$ \\
Anti-HBc Ab & $39(86.67 \%)$ & $6(13.33 \%)$ & $36(80.00 \%)$ & $9(20.00 \%)$ \\
Anti-HCV Ab & $45(100 \%)$ & $0(0 \%)$ & $45(100 \%)$ & $0(0 \%)$ \\
Anti-TP Ab & $45(100 \%)$ & $0(0 \%)$ & $43(100 \%)$ & $0(0 \%)$ \\
Anti-Toxop IgG Ab & $20(45.45 \%)$ & $24(54.55 \%)$ & $26(59.09 \%)$ & $18(40.91 \%)$ \\
Anti-Toxop IgM Ab & $44(97.78 \%)$ & $1(2.22 \%)$ & $42(97.67 \%)$ & $1(2.33 \%)$ \\
Anti-CMV IgG Ab & $22(48.89 \%)$ & $23(51.11 \%)$ & $25(55.56 \%)$ & $20(44.44 \%)$ \\
Anti-CMV IgM Ab & $45(100 \%)$ & $0(0 \%)$ & $43(95.56 \%)$ & $2(4.44 \%)$ \\
Anti-HIV Ab & $45(100 \%)$ & $0(0 \%)$ & $43(95.56 \%)$ & $2(4.44 \%)$ \\
Anti-My Ab & $43(95.56 \%)$ & $2(4.44 \%)$ & $44(100 \%)$ & $0(0 \%)$ \\
\hline
\end{tabular}


TABLE 2. Comparative analysis of pre- and postoperative laboratory tests (complete blood count and biochemical analysis)

\begin{tabular}{|c|c|c|c|}
\hline & $\begin{array}{c}\text { Preoperative } \\
\text { Mean } \pm \text { SD (median) }\end{array}$ & $\begin{array}{c}\text { Postoperative } \\
\text { Mean } \pm \text { SD (median) }\end{array}$ & $p$ value \\
\hline Hematocrit (\%) & $38.31 \pm 5.45$ (39.9) & $33.83 \pm 4.30(33.30)$ & 0.0026 \\
\hline Hemoglobin (g/dL) & $12.16 \pm 2.20(12.40)$ & $11.00 \pm 1.22(11.00)$ & 0.0113 \\
\hline Red blood cells (mil/ $\mu \mathrm{L}$ ) & $4.58 \pm 0.58(4.70)$ & $3.75 \pm 0.62(3.72)$ & $<0.0001$ \\
\hline White blood cells $(/ \mu \mathrm{L})$ & $9,726 \pm 3,597(8,565)$ & $12,419 \pm 18,836(7,675)$ & 0.14 \\
\hline Platelets $(/ \mu \mathrm{L})$ & $212,375 \pm 89,045(221,000)$ & $241,153 \pm 92,311(233,500)$ & 0.34 \\
\hline Urea (mg/dL) & $51.23 \pm 27.59(42.50)$ & $61.13 \pm 30.87(56.74)$ & 0.0218 \\
\hline Creatinine(mg/dL) & $1.01(0.54-1.82)$ & $0.80(0.23-6.00)$ & 0.0008 \\
\hline ASAT (U/L) & 32.55 (12.68-172.1) & $21.5(6.0-139.6)$ & 0.0010 \\
\hline ALAT (U/L) & 32.02 (6.0-226.9) & 34.66 (6.0-239.0) & 0.62 \\
\hline Gamma GT (U/L) & $65.0(15.95-525.8)$ & $87.0(27.0-462.8)$ & 0.03 \\
\hline $\mathrm{LDH}(\mathrm{U} / \mathrm{L})$ & $362.0(156.0-797.0)$ & 320.0 (176.0-871.0) & 0.6477 \\
\hline Direct bilirubin (mg/dL) & $0.68(0.20-3.99)$ & $0.34(0.0-3.200)$ & 0.0007 \\
\hline Total bilirubin (mg/dL) & $1.73(0.18-4.14)$ & $0.685(0.14-2.22)$ & $<0.0001$ \\
\hline Serum proteins (g/dL) & $6.75 \pm 0.96(6.50)$ & $5.43 \pm 2.18(6.03)$ & 0.013 \\
\hline Albumin (g/dL) & $4.13 \pm 0.61(4.21)$ & $3.80 \pm 0.62(3.90)$ & 0.07 \\
\hline Uric acid (mg/dL) & $7.97 \pm 3.13(7.55)$ & $5.65 \pm 2.68(4.49)$ & 0.0004 \\
\hline Cholesterol (mg/dL) & $171.1 \pm 70.11(165.0)$ & $220.1 \pm 63.38(214.8)$ & 0.0033 \\
\hline Triglycerides (mg/dL) & $117.7 \pm 67.93(109.5)$ & $124.5 \pm 66.41(115.8)$ & 0.85 \\
\hline $\mathrm{K}(\mathrm{mmol} / \mathrm{L})$ & $3.75 \pm 0.711(3.90)$ & $4.20 \pm 0.59(4.32)$ & 0.0037 \\
\hline $\mathrm{Na}(\mathrm{mmol} / \mathrm{L})$ & $123.3 \pm 42.30(138.2)$ & $138.1 \pm 2.42(138.0)$ & 0.20 \\
\hline Glucose (mg/dL) & $109.9 \pm 17.15(106.0)$ & $111.9 \pm 28.07$ (109.8) & 0.78 \\
\hline Tacrolimus (ng/mL) & $8.24 \pm 4.11(6.70)$ & $13.68 \pm 2.29(14.30)$ & 0.06 \\
\hline
\end{tabular}

(69.81\%) received mycophenolate mofetil, and 58.49\% received tacrolimus.

There were $16(30.18 \%)$ deaths in the studied population, of which 5 (9.43\%) were intraoperative.

\section{DISCUSSIONS}

This study included all patients who underwent a heart transplantation between 2000 and 2017 at the Institute of Cardiovascular Diseases and Transplant in Târgu Mureș, Romania. All patients were diagnosed with heart failure ranging from NYHA grade II to IV, and most were diag- nosed with dilated cardiomyopathy. The most frequent comorbidities were diabetes and dyslipidemia. Posttransplant type 2 diabetes is difficult to manage, especially if it is associated with dyslipidemia or high blood pressure, which poses a major risk for heart transplant patients. ${ }^{10,11}$

Viral and bacterial serology was positive only for antiToxoplasma gondii antibodies and anti-Cytomegalovirus IgG antibodies, both in the pre- and postoperative evaluation. The complete blood count showed a decrease in hemoglobin and hematocrit levels after surgery, as expected due to intraoperative blood loss. Interestingly, the

TABLE 3. Pre- and postoperative echocardiography

\begin{tabular}{lccc}
\hline & $\begin{array}{c}\text { Preoperative } \\
\text { Mean } \pm \text { SD (median) }\end{array}$ & $\begin{array}{c}\text { Postoperative } \\
\text { Mean } \pm \text { SD (median) }\end{array}$ & p value \\
\hline Left ventricular ejection fraction (\%) & $25.95 \pm 11.34(25.00)$ & $61.18 \pm 5.86(60.00)$ & $<0.0001$ \\
Left atrium diameter (mm) & $48.52 \pm 6.77(49.00)$ & $42.48 \pm 4.58(43.00)$ & 0.0001 \\
LV end-diastolic diameter (mm) & $68.61 \pm 13.63(74.00)$ & $45.83 \pm 5.29(45.00)$ & $<0.0001$ \\
LV end-systolic diameter (mm) & $63.70 \pm 14.19(65.00)$ & $39.53 \pm 9.89(42.00)$ & $<0.0001$ \\
RV diameter (mm) & $34.54 \pm 9.46(34.00)$ & $31.58 \pm 5.03(32.00)$ & 0.0778 \\
Systolic pulmonary arterial pressure $(\mathrm{mmHg})$ & $49.71 \pm 15.27(52.50)$ & $35.42 \pm 9.91(35.00)$ & 0.0002 \\
\hline
\end{tabular}


levels of creatinine and hepatic enzymes were also significantly decreased after cardiac transplant, which could be explained by an improvement in cardiac function and hepatic congestion, as well as a better renal perfusion following surgery due to an enhanced left ventricular systolic function. ${ }^{12,13}$

Echocardiographic examination revealed a significantly better left ventricular ejection fraction in the transplanted heart, significantly lower diameters of the left and right cardiac chambers, and lower systolic pulmonary arterial pressure.

Regarding the type of surgery, all patients underwent orthotopic heart transplantation using the bicaval technique with extracorporeal circulation, with or without primary aortic anastomosis or the removal of a cardioverter defibrillator.

As anti-rejection drugs, mycophenolate mofetil and tacrolimus were administered in most cases, as recommended by current guidelines. ${ }^{14,15}$ Post-transplant infections were reported in a percentage of $13.21 \%$, and 5 out of 16 deaths occurred intraoperatively. ${ }^{16}$

\section{CONCLUSIONS}

The present study is a descriptive analysis of patients undergoing heart transplantation for end-stage heart failure. Most patients did not present viral or bacterial infections in the pre-and postoperative evaluation. Hemoglobin and hematocrit levels were significantly lower following surgery, while renal and hepatic function were significantly improved after cardiac transplantation. The most often used surgical technique was orthotopic transplantation using the bicaval technique with extracorporeal circulation, with or without primary aortic anastomosis. The mortality rate was less than half of cases during the study period, and a small number of patients had died during surgery.

\section{CONFLICT OF INTEREST}

Nothing to declare.

\section{REFERENCES}

1. Jabbour A, Macdonald P. Latest Developments in Heart Transplantation: A Review. Clinical Therapeutics. 2015;37:2234-2241.

2. Salyer J, Flattery MP, Joyner PL, et al. Lifestyle and quality of life in long-term cardiac transplant recipients. J Heart Lung Transplant. 2003;22:309-321.

3. Sánchez-Enrique C, Jorde UP, González-Costello J. Heart Transplant and Mechanical Circulatory Support in Patients with Advanced Heart Failure. Rev Esp Cardiol. 2017;70:371-381.

4. Avram R, Laicu S, Ciocârlie T, et al. Clinical and therapeutical particularities of heart failure in elderly. Romanian Journal of Cardiology. 2014;suppl:236-237.

5. López-Sendón J. The heart failure epidemic. Medicographia. 2011;33:363369.

6. Merlo M, Caiffa T, Gobbo M, Adamo L, Sinagra G. Reverse remodeling in Dilated Cardiomyopathy: Insights and future perspectives. IJC Heart \& vasculature. 2018;18:52-57.

7. Carmona M, García-OImos LM, Alberquilla A, et al. Heart failure in the family practice: a study of the prevalence and co-morbidity. Fam Pract. 2011;28:128-133.

8. Kong G, Xu DL, Body R, Yang JB, Mackway-Jones K, Carley S. A belief rule-based decision support system for clinical risk assessment of cardiac chest pain. Eur J Oper Res. 2012;219:564-573.

9. Dag A, Oztekin A, Yucel A, Bulur S, Megahed FM. Predicting heart transplantation outcomes through data analytics. Decision Support Systems. 2017;94:42-52.

10. Valantine H. Cardiac allograft vasculopathy after heart transplantation: risk factors and management. J Heart Lung Transplant. 2004;23:S187-S193.

11. Smooke S, Horwich TB, Fonarow GC. Insulin-treated diabetes is associated with a marked increase in mortality in patients with advanced heart failure. Am Heart J. 2005;149:168-174.

12. Kobashigawa JA, Patel J, Furukawa $H$, et al. Five-year results of a randomized, single-center study of tacrolimus vs microemulsion cyclosporine in heart transplant patients. J Heart Lung Transplant. 2006;25:434-439.

13. Lemaitre F, Antignac M, Fernandez C. Monitoring of tacrolimus concentrations in peripheral blood mononuclear cells: application to cardiac transplant recipients. Clinical Biochemistry. 2013;46:1538-1541.

14. Eisen $\mathrm{HJ}$, Kobashigawa J, Keogh A, et al. Three-year results of a randomized, double-blind, controlled trial of mycophenolate mofetil versus azathioprine in cardiac transplant recipients. J Heart Lung Transplant. 2005;24:517-525.

15. Kobashigawa JA, Miller LW, Russell SD, et al. Tacrolimus with mycophenolate mofetil (MMF) or sirolimus vs. cyclosporine with MMF in cardiac transplant patients: 1-year report. American Journal of Transplantation. 2006;6:1377-1386.

16. Cozzi S, Martini A, Menestrina N, Gazzani S, Schweiger V, Gottin L. Analysis of risk and prognostic factors of mortality in post-transplant patients in the intensive care unit. Crit Care. 2005:9:P234. 